\title{
Investigation of Polymer Matrix Metarials in Automotive Consoles
}

\author{
Mehmet Çakmakkaya ${ }^{1 *}$, Mehmet Kunt ${ }^{1}$, Oğuzhan Terzi ${ }^{1}$ \\ 0000-0002-9031-3830, 0000-0002-2033-6703, 0000-0002-9836-443X
}

${ }^{1}$ Automotive Engineering Department, Faculty of Technology, Afyon Kocatepe University, Afyonkarahisar, 03020, Turkey

\begin{abstract}
Research on reducing the weight of automobiles, achieving fuel consumption and reducing harmful exhaust emissions focuses on the research of new materials. The polymer matrix is the most widely used material for re-spectra for composite applications within the scope of the redial field mentioned above. Because polymer materials are inexpensive and improve their physical and mechanical properties, they are used in many applications to replace metal licensed materials. The front barrier of a car made of glass fiber-reinforced polymer composite material can achieve a 35-mph crash test. In addition to providing the same level of collision safety as steel, poly-mer composites can provide improved performance with features such as vibration control. In this study, the use of plastic materials in the automotive sector and the sections used were examined, the researches were made on the basis of the use of polypropylene materials in the vehicle front consoles and the tensile strength of the samples taken from the front consoles were examined. At least two samples were used for each material type in the experiments. Tensile strength values of the material were obtained with tensile test. The tensile test was carried out at room temperature. Materials were examined according to tensile test results and performance evaluation was made based on tensile strength. According to the results of the evaluation, $\mathrm{C}$ model was found to be the most useful material.
\end{abstract}

Keywords: Console, polypropylene, plastic, tensile strength.

\author{
* Corresponding author \\ Mehmet Çakmakkaya \\ cakmakkaya@aku.edu.tr
}

Adress: Automotive Engineering Department, Faculty of Technology, Afyon Kocatepe University, Afyonkarahisar, Turkey

Tel:+902281446-15200

Fax: +902281449

Research Article

Manuscript Received 16.01.2019

Revised 10.09.2019

Accepted 22.09.2019

Doi: 10.30939/ijastech..513332

\section{Introduction}

In the recent decade, polymers have become attractive materials for various applications due to several attractive properties, including light weight, ease of processing and cost-effectiveness. Hence, attempts have been significantly made to utilize polymers in different industrial applications, using various kinds of reinforcements including fibers that are incorporated into the polymers to increase their physical and mechanical properties. Thus, fiber reinforced polymer matrix composites are extensively attractive due to their light weight, biodegradability [1], high strength [2], [3], high stiffness [4], good corrosion resistivity [5] and low friction coefficient [6] in many applications that are important in mechanical and tribological properties, from households to aerospace applications and, today, these materials are used in nearly all areas of daily life [7], [8], [9].
Polyolefins in automobiles have experienced a great deal of interest in the last twenty years, and their applications have been increasing with a tendency of further growth compared with other materials used in automobiles. The demand for lightweight materials for the automobiles is gradually gaining prominence due to the continuously rising demands to reduce fuel consumption. The use of polyolefin materials in automobile applications has been increasing dramatically. Their functionality, cost-effective manufacturing methods, and comparatively lower fuel consumption are the key factors in selecting these materials compared to other materials applied in automobiles [10]. A wide array of reinforcing additives is available for strengthening the plastic materials. These additives include cellulosic fibers, coconut fibers, jute chippings, palm fibers, bamboo fibers, paper wastes, whole wheat flour, wood chippings and kraft pulp, and are incorporated in the composi- 
tion of the plastic materials. Furthermore, thermoplastic resins are added in plastics as binding agents. The $10 \%$ of waste fibers are produced through breaking up the hemp leaves and shaping the raw fibers in cord forms. Such waste fibers are considered desirable both for reducing production costs and for improving the physical and mechanical properties of fiber polymer reinforced composites further [11].

Plastic materials with reinforced polymer matrix are capable of various types of loading conditions during their utilization. The most significant of these conditions are mechanical stresses and environmental impacts. Temperature, humidity, radiation, various chemicals are considered as the main environmental factors. Such factors could diversely affect the thermal and mechanical properties of reinforced plastics [12].

Several researchers investigated the effectiveness, appropriateness and capacities of natural fibers, when used as fillers for strengthening polymer matrix materials. Majority of researchers focused on subjects such as mechanical properties, chemical modifications to improve fiber/polymer compatibility, production processes and other technical issues. Others conducted comparative research on reinforced polymer composites in order to demonstrate the appropriateness of polymers for specific purposes and applications [13].

Polyurethanes are used for various applications in diverse areas. For instance, they are commonly used in the form of elastomers, adhesives and coatings. In coating applications, the most significant contribution expected from coating materials is the resistance against scratches and environmental factors. Furthermore, a surface coating is capable of exhibiting more specific features beyond the abovementioned properties, thus has a wide range of use. The properties of polyurethanes, such as corrosion resistance, thermal stability and resistance to environmental degradation increased their current use in coating applications [14].

A fiber reinforced polymer (FRP) is a reinforced polymer matrix composite material obtained through the addition of high strength fibers such as glass, aramid and carbon. In general, it is possible to classify polymers as thermoplastics and thermosetting. Currently, bio-fiber matrix thermoplastic polymers are being widely used in the production of various materials. The commonly used thermoplastics, with respect to above considerations, are polypropylene (PP), polyethylene and polyvinyl chloride (PVC), phenolic, epoxy and polyester resins, acrylonitrile butadiene styrene (ABS), polyamide (PA), polyethylene (PE), polycarbonate (PC) and are thermosetting matrices. In recent years, natural fibers, an alternative reinforcement in polymer composites, became a focus of attention for numerous researchers and scientists due to their advantages over conventional glass and carbon fibers. Natural and synthetic fibers were presented in Table 1.
Table 1. Properties of several natural and synthetic fibers used as additives in polymers [15].

\begin{tabular}{|c|c|c|c|c|}
\hline Fibers & $\begin{array}{r}\text { Density } \\
\mathrm{g} / \mathrm{cm} 3\end{array}$ & $\begin{array}{c}\text { Expansion } \\
\%\end{array}$ & $\begin{array}{l}\text { Tensile } \\
\text { Strength } \\
\text { (MPa) }\end{array}$ & $\begin{array}{c}\text { Elastic } \\
\text { Module } \\
(\mathrm{GPa})\end{array}$ \\
\hline Cotton & $1.5-1.6$ & $7.0-8.0$ & 400 & $5.5-12.6$ \\
\hline $\begin{array}{l}\text { Indian } \\
\text { Hemp }\end{array}$ & 1.3 & $1.5-1.8$ & $393-773$ & 26.5 \\
\hline Linen & 1.5 & $2.7-3.2$ & $500-1500$ & 27.6 \\
\hline Hemp & 1.47 & 2-4 & 690 & 70 \\
\hline $\begin{array}{l}\text { Hemp } \\
\text { Fiber }\end{array}$ & 1.45 & 1.6 & 930 & 53 \\
\hline $\begin{array}{l}\text { Ramie } \\
\text { Fiber }\end{array}$ & N/A & $3.6-3.8$ & $400-938$ & $61.4-128$ \\
\hline $\begin{array}{c}\text { Sisal } \\
\text { Hemp } \\
\text { Fiber }\end{array}$ & 1.5 & $2.0-2.5$ & $511-635$ & $9.4-22$ \\
\hline $\begin{array}{c}\text { Coconut } \\
\text { Fiber }\end{array}$ & 1.2 & 30 & 593 & $4.0-6.0$ \\
\hline $\begin{array}{l}\text { Kraft } \\
\text { Paper }\end{array}$ & 1.5 & 4.4 & 1000 & 40 \\
\hline $\begin{array}{l}\text { Raw } \\
\text { Material }\end{array}$ & & & & \\
\hline $\begin{array}{l}\text { E-glass } \\
\text { Fiber }\end{array}$ & 2. 5 & 0.5 & $2000-3500$ & 70 \\
\hline $\begin{array}{c}\text { S-glass } \\
\text { Fiber }\end{array}$ & 2.5 & 2.8 & 4570 & 86 \\
\hline $\begin{array}{l}\text { Flexten } \\
(\text { Std })\end{array}$ & 1.4 & $3.3-3.7$ & $3000-3150$ & $63.0-67.0$ \\
\hline $\begin{array}{l}\text { Carbon } \\
\text { (Std. PAN } \\
\text {-based) }\end{array}$ & 1.4 & $1.4-1.8$ & 4000 & $230-240$ \\
\hline
\end{tabular}

Composites constitute a class of materials that contain two or more different components with significantly different physical and/or chemical properties. Generally, a composite structure includes a strong and rigid reinforcement element. Such reinforcement elements are embedded in the soft structure of a matrix phase. Obtained new composite materials have higher mechanical properties structurally. Numerous natural materials have intrinsically composite characteristics. For instance, wood fibers consist of cellulose and hemicellulose microfibrils embedded in a lignin amorphous matrix. Bones and teeth are inorganic crystalline structures, also composed of collagen matrix. It is possible to classify composites in three based on the type of matrix used: I. polymer matrix composites (PMC), II. metal matrix composites (MMC) and III. ceramic matrix composites (CMC). Majority of the artificial composites include unsaturated polyesters such as poly(ethylene), poly(propylene), poly(vinyl chloride) and poly(ethylene oxide), thermoset resins and polymers such as phenolic resin, epoxy resin, rubber and thermoplastic polymers. There are significant research efforts to produce biodegradable polymer composites such as poly(lactic acid), poly(hydroxybutyrate), starch-, cellulose- and oli-(hydroxyoxanoate) due to the growing concern on sustainability and environmental protection. Glass strengthened plastics (GRP) are widely used in air crafts, automobiles, sea crafts, storage tanks, construction and piping applications, due to their improved strength, 


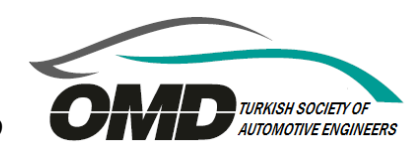

lightweight properties and resistance to chemicals in comparison to steel [16].

\subsection{Polymer Matrix Composites}

Polymers (Greek: poly "many", meros "fragments", meaning: multipartite) are molecules with very long chains formed by a repetitive interlocking of relatively small molecules called the monomers [17].

There exist three types of polymers, namely, thermosets, thermoplastics and elastomers.

- Thermosets: Polyester, epoxy, phenol formaldehyde

- Thermoplastics: Polyethylene polycarbonate, nylon

- Elastomers: Rubber, polybutadiene, polychloroprene [17].

The present study conducts a tensile strength experiment on the front consoles of different automobile models, which were produced with different materials such as the PP, ABS, PA, PC, and PE. Tensile strength results obtained for different automobile brands were evaluated as a result of this experiment. Based on the results of the experiment, it was determined that different materials should be used due to distinct factors such as cost, security and quality.

\section{Materials and Methods}

\subsection{Tensile Strength Experiment}

Commonly, polymer materials demonstrate three different behaviors related to stress and unit deformation. For instance, polymers acknowledged as elastomers are damaged as a result of complete elastic deformation. There exist structural polymers, which primarily exhibit elasticity up to the yielding point and then plastic deformation as observed in various metals, and brittle polymer materials that are damaged due to deformation without exhibiting any levels of plasticity. For automotive interior parts such as seat covers and dashboards, the use of these composites can reduce the cost of PVC as well as improve the overall strength of the parts. In terms of weight, CSP can reduce the overall weight of these parts through lowering of the composite density, and hence can improve the fuel efficiency. For engine parts, these composites can replace steel (even PVC material in the air intake piping system) because of its advantages. By using these composites, it can reduce a cost of base polymer and also can decrease the effect of environmental issues concerning energy and carbon credits $[19,20]$.

Currently, mechanical test methods are being used to identify the material properties based on area of application. The test methods focusing on the determination of the tensile strength, elastic module and percentage elongation of the material helps to clarify the material performance based on the parts that the material would be used.

The most basic experiment in investigating the relations between stress and deformation is the tensile test. Tensile test is conducted with the intent to determine the elastic and plastic behavior (mechanical properties) of materials under static loading, to classify materials based on their mechanical behavior and to select materials appropriately. Yield strength $(\sigma \mathrm{y})$, tensile strength (TS) and percentage elongation $(\%)$ values obtained from tensile test specimens are considered as significant criteria in material selection.

The mechanical properties of the materials are evaluated based on the comparison of the values obtained via the tensile tests. The tensile strength value for polymers is generally considered as their strength value.

The specimens used in the experiment were compressed between the retaining jaws in the tensile test equipment. In order to stretch the materials, the retaining jaws on the test equipment were controlled to separate from each other at a constant velocity. The fixed velocity value determined in applying the tensile stress is a value that depends on the type of the material. The specimens were attached from two ends to the jaws of the tensile test equipment and tensile stress was applied with an increasing load until it breaks. During this procedure, the applied load $\mathrm{F}$ and the elongation of the material under loading are measured. The load $(F)$ and elongation $(\Delta \mathrm{L})$ values obtained as the results of the experiment are presented in the $(\mathrm{F}-\Delta \mathrm{L})$ graph [18].

\subsection{Preparation of the Test Specimen}

The test specimens were prepared based on the ASTM D 792 standards, using a water jet cutter. The trademark for the tensile test equipment used in the present study was AUTOGRAPH. The specimens prepared for the tensile strength test were carefully placed between the retaining jaws and the experiments were carried out at a constant tensile speed of $2 \mathrm{~mm} / \mathrm{min}$.

The test specimens used in the present study were obtained from two different models of two different automobile brands. The tensile test specimens, which were retrieved from the front consoles of the selected automobiles, were coded as A, B, C and D. Figure 1 and Figure 2 present the dimensions and appearance of the coded tensile test specimens.

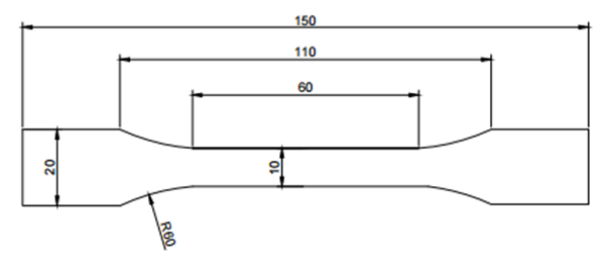

Fig. 1. Specimen standards for tensile testing 


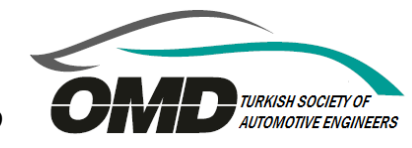

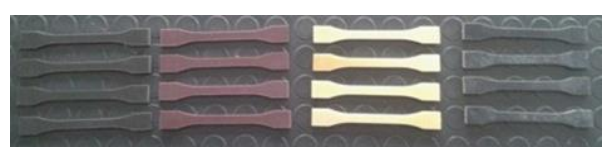

Fig. 2. Tensile test specimens used in the experiments

An Instron 5567 Universal Testing Machine equipped with $30 \mathrm{kN}$ load cell, a mechanical clamping device and an extensometer were used to measure the tensile strength and flexural strength of the samples. The measure of tensile stress was carried out according to ASTM D638 standard with a dumbbell shape and was determined according to the Equation (1) while Modulus of elasticity was determined by using Equation (2).

$\sigma_{t}=\frac{F}{A}$

Where $\sigma_{t}$ is the tensile stress, $\mathrm{F}$ is the force at the fracture point and $\mathrm{A}$ is the cross sectional area.

$$
\mathrm{E}=\frac{\sigma_{t}}{\varepsilon}
$$

Where $\mathrm{E}$ is Young Modulus of Elasticity and $\varepsilon$ is the strain. A flexural stress test was carried out according to the ASTM D790 standard and was determined according to Equation (3).

$$
\sigma f=\frac{3 F L}{2 b d^{2}}
$$

Where $\sigma f$ is the flexural stress, $\mathrm{L}$ is the length of support span $(\mathrm{mm}), \mathrm{b}$ is the width of specimen $(\mathrm{mm})$ and $\mathrm{d}$ is the thickness of specimen (mm).

\section{Experimental Study}

In the experimental setup, two specimens were used for each type of material. As a result of the tensile strength experiment the tensile strength and elastic module of the materials were obtained. The tensile test was conducted at room temperature, with a deformation velocity of 2 $\mathrm{mm} / \mathrm{min}$. Table 2 presents the mechanical properties obtained as a result of the experiment.

Figure 3, 4, 5, and 6 present the break points for the specimens that belong to four different models, as a result of the tensile strength test.

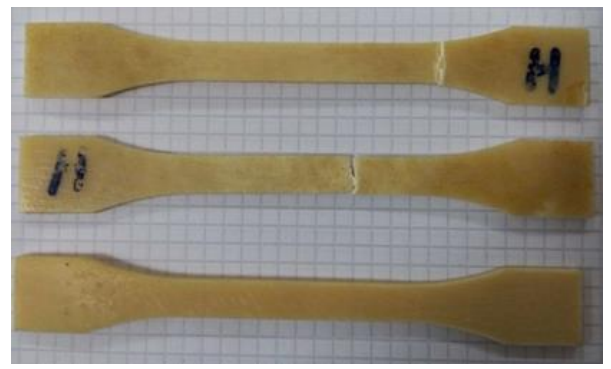

Fig. 3. Specimens that were broken due to the tensile strength test (Model A)

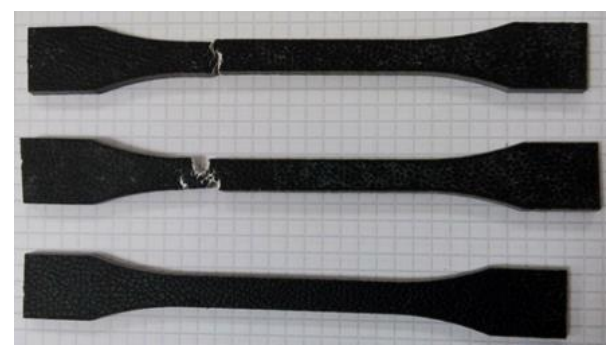

Fig. 4. Specimens that were broken due to the tensile strength test (Model B)

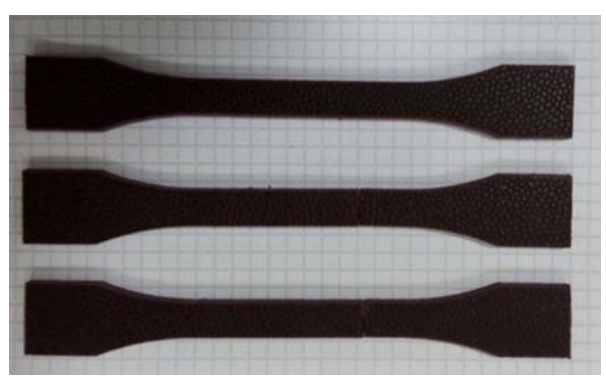

Fig. 5. Specimens that were broken due to the tensile strength test (Model C)

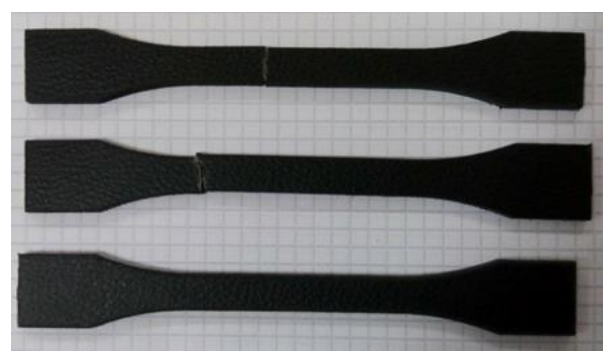

Fig. 6. Specimens that were broken due to the tensile strength test (Model D) 
Table 2. The mechanical properties of the specimens at room temperature.

$\begin{array}{cccc}\begin{array}{c}\text { Automobile } \\ \text { type }\end{array} & \begin{array}{c}\text { Tensile } \\ \text { Strength } \\ (\mathrm{MPa})\end{array} & \begin{array}{c}\text { Yielding } \\ \text { Strength } \\ (\mathrm{MPa})\end{array} & \begin{array}{c}\text { Elongation } \\ \text { at time of } \\ \text { breaking } \\ (\%)\end{array} \\ \begin{array}{c}\text { Automobile } \\ \text { Model A }\end{array} & 54.8667 & 50.5167 & 4.19242 \\ \begin{array}{c}\text { Automobile } \\ \text { Model B } \\ \text { Automobile } \\ \text { Model C }\end{array} & 16.2878 & 8.01 & 3.847 \\ \begin{array}{c}\text { Automobile } \\ \text { Model D }\end{array} & 18.3667 & 6.465 & 5.45424 \\ & & & \end{array}$

\section{Conclusion and Discussions}

The mechanical behavior of polymer materials, which were determined as the outcomes of tensile strength tests, provides information about their elastic deformations. Determination of the yield and tensile strength values of polymer materials indicated that these materials should be evaluated different than metal materials. However, percentage elongation values were found to have similar values to that of metals. According to the results of this experiment;

Maximum tensile strength was seen in model 1 Plastic without deformation max. The model with the highest elongation percentage is the model 4 therefore, the ductile material belongs to the model 2 the lowest model is the first model. Therefore, the most brittle material belongs to model 1 .

The highest elongation was observed in the material of the second model. However, the material showing the maximum elongation without plastic deformation from the samples belongs to the model 4 . The maximum elongation percentage of the sample of model 4 is lower than that of Model 2. Therefore, the material of model 4 may be preferred.

According to the results of this study, it is seen that polymer materials are superior to each other and are open to development. The studies on polymer materials will lead to solutions that will reduce the cost of automotive parts, will help to reduce the weight of the vehicles and will increase the alternative materials.

Different models of different automobiles do not include materials with identical mechanical properties. Such finding stems from the fact that the additive materials used in strengthening polymers have different properties. The selection of the products used for strengthening the polymer materials are considered with respect to their availability in the market, besides their mechanical properties, and the selection criteria for such materials are determined accordingly.

It is possible to conclude that, today, the products obtained as a result of manufacturing are selected, taking both the visual and the economic properties into consideration.

\section{References}

[1] Thakur, V.K., Thakur, M.K., Gupta, R.K. (2014). Review: raw natural fiber-based polymer composites. Int. J. Polym. Anal. Charact, 19, 256-271.

[2] Ku, H., Wang, H., Pattarachaiyakoop, N., Trada, M. (2011). A review on the tensile properties of natural fiber reinforced polymer composites. Compos. Part B Eng, 42, 856-873.

[3] Barari, B., Ellingham, T., Qamhia, I., Pillai, K., El-Hajjar, R., Turng, T. et al. (2016). Mechanical characterization of scalable cellulose nano-fiber based composites made using liquid composite molding process. Compos. Part B Eng 277-284.

[4] Unterweger, C., Brüggemann, O., Fürst, C. (2014). Synthetic fibers and thermoplastic short-fiber-reinforced polymers: properties and characterization. Polym. Compos, 35, 227-236.

[5] Santos, T., Vasconcelos, G., Souza, W., Costa, M., Botelho, E. (2015). Suitability of carbon fiber-reinforced polymers as power cable cores: Galvanic corrosion and thermal stability evaluation. Mater Design, 65, 780-788.

[6] Pei, X-Q., Bennewitz, R., Schlarb, A.K. (2015). Mechanisms of friction and wear reduction by carbon fiber reinforcement of Peek. Tribol Lett, 58, 1-10.

[7] Bahadur, S., Zheng Y. (1990). Mechanical and tribological behavior of polyester reinforced with short glass fibers. Wear, 137, 251-266.

[8] Zhang, S. (1998) State-of-the-art of polymer tribology Tribol. Int 31, 49-60.

[9] Zhang, Y., Zhu, S., Liu, Y., Yang, B., Wang, X. (2015). The mechanical and tribological properties of nitric acid-treated carbon fiber-reinforced polyoxymethylene composites $J$. Appl. Polym. Sci, 132.

[10]Cintil Jose Chirayil, Jithin Joy, Hanna J. Maria, Igor Krupa, Sabu Thoma, (2015). Polyolefins in Automotive Industry. Polyolefin Compounds and Materials pp 265-283

[11]Claire S. Boland, Robb De Kleine, Gregory A. Keoleian, Ellen C. Lee, Hyung Chul Kim, and Timothy J. Wallington, (2016). Life Cycle Impacts of Natural Fiber Composites for Automotive Applications: Effects of Renewable Energy Content and Lightweighting. Journal of Industrial Ecology Volume20, Issue1 Pages 179-189

[12]Herrera-Franco, P.J. and Valadez-Gonza'lez, A. (2004). Mechanical properties of continuous natural fibre-reinforced polymer composites. Composites Part A 35, 339-345.

[13]Selzer R. and Friedrich K. (1997). Mechanical properties and failure behaviour of carbon fibre-reinforced polymer composites under the influence of moisture, Composites Part A 28A, 595- 604.

[14]Faris M. AL-Oqla, Sapuan, S.M. (2014). Natural fiber reinforced polymer composites in industrial applications: feasibility of date palm fibers for sustainable automotive industry. Journal of Cleaner Production 66, 347-354.

[15]Phetphaisita, C. W., Namahoota, J., Saengkiettiyutb, K., Ruamcharoenc, J. (2015). Polphat Ruamcharoen Green metal 
organic coating from recycled PETs and modified naturalrubber for the automobile industry. Progress in Organic Coatings 86, 181-189.

[16]Ku, H., Wang, H., Pattarachaiyakoop, N., Trada, M. (2011). A review on the tensile properties of natural fiber reinforced polymer composites, Composites: Part B 42, 856-873.

[17]Miao, C. and Hamad, W.Y. (2013). Cellulose reinforced polymer composites and nanocomposites: a critical review, Cellulose, 20:2221-2262.

[18]Saffet, G (2018-Ocak). Otomotiv Endüstrisinde Kullanılan Polimer Matrisli Kompozit Malzemeler, Yüksek Lisans Tezi, Pamukkale Üniversitesi, Fen Bilimleri Enstitüsü.

[19]Muhammad Hanafi Md S. (2017). Mechanical Properties of Coconut Shell Powder Reinforced PVC Composites in Automotive Applications, Journal of Mechanical Engineering, Vol 14(2), 49-61.

[20]Savaşçı, Ö.T., Uyanık, N., Akovalı, G. (1999). Plastikler ve Plastik Teknolojisi, PAGEV Yayınları, İstanbul. 